\title{
Overview of High Impact Practices for Improved Prevention, Detection, and Management of Hypertensive Disorders in Pregnancy
}

Population Council

Follow this and additional works at: https://knowledgecommons.popcouncil.org/departments_sbsr-rh

Part of the Maternal and Child Health Commons How does access to this work benefit you? Let us know!

\section{Recommended Citation}

"Overview of High Impact Practices for Improved Prevention, Detection, and Management of Hypertensive Disorders in Pregnancy," High Impact Practices brief. Washington, DC: Population Council, 2020. 


\section{Overview of High Impact Practices for Improved Prevention, Detection, and Management of Hypertensive Disorders in Pregnancy}

\section{Population Council, supported by the Pre-eclampsia Technical Working Group, developed High Impact Practice briefs for three strategies that show promise for improving prevention, detection, and management of hypertensive disorders in pregnancy.}

Hypertensive Disorders in Pregnancy (HDPs), affect 10 percent of women globally and are major contributors to maternal and newborn mortality, morbidity, and disability $[1,2]$. While the exact cause of eclampsia is unknown, we know how to prevent and manage it. Providing essential services and health education for women at all levels of the health system is necessary to improve survival rates and quality of life for women who experience HDPs (including eclampsia) and their newborns.

Inspired by the Family Planning High Impact Practices (HIPs), we adapted this approach to evidence sharing in order to build consensus around what works for HDPs. The development of these briefs was led by the Population Council's Ending Eclampsia Project with contributions from global experts.

Population Council conceived the idea to create HIPs for HDPs as part of the Ending Eclampsia Project. The preeclampsia Technical Working Group (TWG) expressed interest and support for this activity. The concept was discussed with the TWG in May 2018 and several best practices topic areas were reviewed in February 2019. This was followed by a TWG meeting in May 2019 to prioritize topics for HIPs briefs. Over 40 experts (researchers, practitioners, donors, and advocates) identified and agreed on three key topics, which had the most evidence for their use to improve health outcomes for HDPs including pre-eclampsia.

1. Task Sharing for hypertensive disorders in pregnancy: Task share key interventions to increase the healthcare workforce with the skills to identify high risk women and prevent, detect, and manage women with hypertensive disorders in pregnancy and the postnatal period.

2. Encouraging empowerment and self-care through participatory women's groups and group antenatal care: Highly participatory group-based interventions for women during the antenatal and postnatal periods provide information, education and counseling for improved health literacy, improved health seeking behaviors, social support, and opportunities to cultivate empowerment and agency.

3. Detecting and managing hypertension in the postnatal period: All women should have their blood pressure checked and recorded immediately after delivery and daily until discharge. Specifically: at least once between Day 3 and 5, again, at the 6 week and 3-month postnatal check, and at any other contact with the health system. Appropriate treatment of hypertension postnatally is essential to prevent long-term maternal morbidity.

Based on the available evidence, these three strategies show promise for improving prevention, detection, and management of HDPs including pre-eclampsia and eclampsia $(\mathrm{PE} / \mathrm{E})$. Following this consultation, the Ending Eclampsia team conducted extensive literature reviews and developed detailed outlines for each. These outlines were then circulated back to the TWG and those members interested in supporting the development of these briefs provided comments and suggestions on the three outlines. Full drafts were circulated similarly, and feedback solicited twice prior to the reconvening of the TWG in November 2019 to review final drafts of the three briefs prior to publication.

\section{REFERENCES}

1. Duley L. The Global Impact of Pre-eclampsia and Eclampsia. Semin Perinatol. 2009;33(3):130-7.

2. Say L, Chou D, Gemmill A, Tunçalp Özge, Moller AB, Daniels J, et al. Global causes of maternal death: A WHO systematic analysis. Lancet. 2014;2(6):323-33.

For further information please contact us at MNH-PCDC@ popcouncil.org

\footnotetext{
The Population Council conducts research and delivers solutions that improve lives around the world. Big ideas supported by evidence: It's our model for global change. popcouncil.org

(C) 2020 The Population Council, Inc.
}

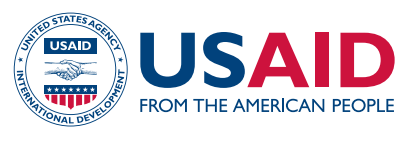

\section{ENDING}

